\title{
Information sharing systems and teamwork between sub-teams: a mathematical modeling perspective
}

\author{
Hamid Tohidi $^{1} \cdot$ Alireza Namdari $^{2} \cdot$ Thomas K. Keyser $^{2} \cdot$ Julie Drzymalski $^{3}$
}

Received: 9 May 2016/ Accepted: 24 March 2017 / Published online: 18 April 2017

(c) The Author(s) 2017. This article is an open access publication

\begin{abstract}
Teamwork contributes to a considerable improvement in quality and quantity of the ultimate outcome. Collaboration and alliance between team members bring a substantial progress for any business. However, it is imperative to acquire an appropriate team since many factors must be considered in this regard. Team size may represent the effectiveness of a team and it is of paramount importance to determine what the ideal team size exactly should be. In addition, information technology increasingly plays a differentiating role in productivity and adopting appropriate information sharing systems may contribute to improvement in efficiency especially in competitive markets when there are numerous producers that compete with each other. The significance of transmitting information to individuals is inevitable to assure an improvement in team performance. In this paper, a model of teamwork and its organizational structure are presented. Furthermore, a mathematical model is proposed in order to characterize a group of sub-teams according to two criteria: team size and information technology. The effect of information technology on performance of team and sub-teams as well as optimum size of those team and sub-teams from a productivity perspective are studied. Moreover, a quantitative sensitivity analysis is presented in order to analyze the interaction between these two factors through a sharing system.
\end{abstract}

Hamid Tohidi

h_tohidi@azad.ac.ir

1 College of Industrial Engineering, South Tehran Branch, Islamic Azad University, Tehran, Iran

2 College of Engineering, Industrial Engineering Department, Western New England University, Springfield, MA, USA

3 Drexel University, Philadelphia, PA 19104, USA
Keywords Teamwork - Team size $\cdot$ Sub-team · Information technology $\cdot$ Information sharing system . Productivity

\section{Introduction}

Productivity is a proof of total efficiency of production process and also a subject of maximization. It is determined by comparing the quantity of output and input and is also considered to be a significant measure of any economy, industry, and company's development. However, it requires an appropriate identification of real inputs and outputs within a business. Productivity is one of the considerable concerns of engineering management, so that it has been causing companies to follow procedures of collecting and analyzing data in order to evaluate their performance. Productivity improvement stems from a certain degree of complex interaction among factors. Teamwork and IT are two decisive factors which may cause immediate effect on the way productivity can be improved. Investing in ICT capital increases firm productivity by increasing the productivity of labor (Kılıçaslan et al. 2017).

Historically, teamwork has been defined as a process of working collaboratively within a group of individuals when team members pursue an identified goal. Teamwork is an integral part of progress in today's world. It has increasingly become prevalent among enterprises to benefit from teamwork. However, team members play a prominent role in consequences of teamwork. Every team member has particular responsibilities in order to accomplish tasks.

Information technology (IT), typically, refers to a set of applications to transmit, save, recover, and report data in the context of a business. However, it is mistakenly used in reference to personal or home computers. It actually 
involves all facets of managing information, data manipulation, and data storage architectures and methodologies. IT may contribute to improving organizational performance and productivity by assuming different variables. IT is a broad subject concerned with a range of attributes from personal computing and networking to information sharing system (ISS) within an organization. ISS consists of all layers of system from hardware to database and data management techniques. It is shown that the impact of IT capital on productivity is larger by about $25-50 \%$ than that of conventional capital. This contribution of IT capital is higher than that of non-ICT capital for small sized and lowtech firms (Kilıçaslan et al. 2017).

Team size is an effective parameter in teamwork. Studies in this field have shown that as team size increases the outcome will improve. However, team size contributes to productivity, but after a certain point the law of diminishing returns occurs which means adding to the team members will not result in a better team performance and improvement in productivity because of the irrational additional team size. Value-added analysis may be the solution in this regard.

In this research, a mathematical model is proposed to explain how teamwork may affect the productivity while considering information technology and optimized size of team and sub-teams as two effective factors. Teamwork may be processed within either a team or a group of subteams. In this study, a team with a group of sub-teams is presented. Furthermore, the size of team and sub-teams are investigated.

The related work is categorized according to two primary themes: productivity affected by teamwork and productivity affected by information technology. The following subsections address the mentioned research interests.

\section{Productivity affected by teamwork}

Literatures on efficiency and productivity mainly focus on relations between teamwork and productivity and the importance of team size is not addressed. Stewart and Barrick (2000) examined data from many different teams including individuals and supervisors to resolve the appropriate structure. They studied the relationships between all characteristics and performances for both conceptual and behavioral tasks and how the nature of the tasks may affect the consequences. Salas et al. (2008) reviewed the developments in team performance in five recent decades. They studied the shared cognition, team training, and task environments mainly from a human factor perspective. Moses and Stahelski (1999) studied the relation between productivity in an aluminum plant and problem-solving teams. Five productivity measures and four time periods in 1980s and 1990s were analyzed and significant and non-significant changes between the time periods were evaluated. The results were compared with three factors, technology improvements, changes in the price of finished aluminum, and changes in the number of employees. It was concluded that the study was not affected by those factors. Hatcher and Ross (1991) used different methodologies to analyze the changes in a transition from individual piecework plan to a gain-sharing plan at a company. The data observed in 4 years of operating presented a decrease in grievances and increase in final quality. Galegher and Kraut (1994) studied contingency theory to prove the difficulties of computer-based communication in order to reach complex collaborative work. A group of $67 \mathrm{MBA}$ students was considered to do two writing projects in three different conditions; Computer, Computer plus Phone, and Face-to-Face. That study presented the difficulty of tasks which involve ambiguous goals, multiple perspectives, and multi-interpretation information using contingency hypothesis. Powell (2000) modeled a production process including variable processing times for different tasks in order to determine the optimal size of teams. In this research, the conditions under which assigning small tasks to individuals in comparison with assigning complex tasks to large teams were addressed. It was found that depending on the parameters different structures may be preferred.

\section{Productivity affected by IT}

IT has received increasing academic attention in the last two decades. Explained ahead, improving IT may cause improvement in efficiency. Bharadwaj (2000) studied IT capabilities and firm performance based on experiments by using a matched-sample methodology and ratings. IT resources in the area of firm were categorized into IT infrastructure, human IT resources, and IT-enabled intangibles. It was demonstrated that firms with high IT capability may contribute to cost-based performance measures. Whelan (2002) examined the importance of IT in general and computer in particular in productivity, calculated the computer-usage effect in US economic growth, and developed a theoretical framework to study the technological obsolescence. Bartel et al. (2005) presented new empirical indications regarding the investments in new computer-based IT and productivity. In this research, a set of data was reviewed to examine the effects of new IT on production innovation, process improvements, employee skills, and work practices. The authors showed how new IT adoption may be defined more than new equipment installation. Furthermore, IT was studied as a factor which alters business strategies, improves the efficiency of production process, and increases the skill requirements of 
members. Badescu and Garcés-Ayerbe (2009) collected data from 341 medium size and large firms to evaluate the effects of investment in IT on productivity by using a Cobb-Douglas function. In this research, the effect of IT was categorized into firm-specific and period-specific and a significant improvement in productivity derived from IT was not observed within the defined time periods. Dehning and Richardson (2002) developed a model to assess investment in IT based on the data gathered from firm accounting and market performance. However, the relation between IT and business process on one hand, and business process and firm performance on the other hand were examined. Furthermore, the effects of contextual factors on performance of IT and IT management on performance of firm were reviewed. Wu et al. (2014) focused on two main concerns, information sharing and collaborative effort but in a supply chain context and identified the rudiments of implementing them in terms of issues related to partner exchanges including trust, commitment, reciprocity, and power. Finally, a positive relation between set-based variables, information sharing and collaboration, and supply chain performance was concluded. Martínez-Lorente et al. (2004) presented a survey-based research on the significant relationships between information technology (IT) and total quality management (TQM). However, the survey was conducted within the largest industrial companies in Spain and the results showed that intensive IT users observe the effect of IT on their TQM dimensions more significantly. Shao and Lin (2016) evaluated the performance of IT service industries of Organization of Economic Cooperation and Development (OECD) countries by using Malmquist Productivity Index (MPI) as a metric and Stochastic Production Frontier (SPF) as an approach and an annual rate of $7.4 \%$ growth in productivity in IT service industries was observed. The reported growth in productivity was mainly caused by technological advance process of IT services. Jones et al. (2011) studied the impact of implementing an Enterprise Resource Planning (ERP) system in a retail chain and firm and employee effects of an appropriate information system. It was found that employees need to be informed of implementation of such an information system and the negative outcomes associated with them.

These literatures on productivity only deal with the approaches and models considering either IT or teamwork, and did not present the effect of both issues on production. Explained ahead, there are few researches considering both IT and teamwork at the same time. Tohidi and Tarokh (2006) studied the effect of changing IT on team output. They described the best coordination to increase team output and provided a good example of a team including two assembly lines and a supervisor. In addition, they categorized the factors which impact on coordination to hardware and software. In their research, they addressed the appropriate combination of those two factors from the output perspective. They proposed and analyzed a mathematical model in which productivity is driven by teamwork and information technology. They presented a sensitivity analysis to examine how IT and team size may increase the ultimate output. To the best of our knowledge this work is one of few studies about productivity considering both IT and teamwork. However, a structured model for a team with sub-teams has been lacking. The rest of the paper is organized as follows: first of all a model of teamwork is proposed. Then a mathematical model is produced. After that, interaction between IT and sub-teams is presented. To show the results of the paper as well as possible a sensitivity analysis is prepared in the next step. Finally, conclusion remarks are presented.

\section{The proposed model and problem statement}

Each team member affects output by collaborating with other team members to pursue team objectives. Coordination between team members is expected to lead to a considerable output. The issue of concern is how we can provide the best coordinated teamwork to improve output. With additional effort, according to the law of diminishing returns it will result in a decrease in output. This should be studied in order to determine the optimum size of each subteam, and value of information related to each individual to benefit from a better collaboration.

As depicted in Fig. 1, in the presented model we assume a team size of $n$ which contains $m$ subgroups with $n_{\mathrm{s}}$ individuals in each of them producing product $\mathrm{X}$.
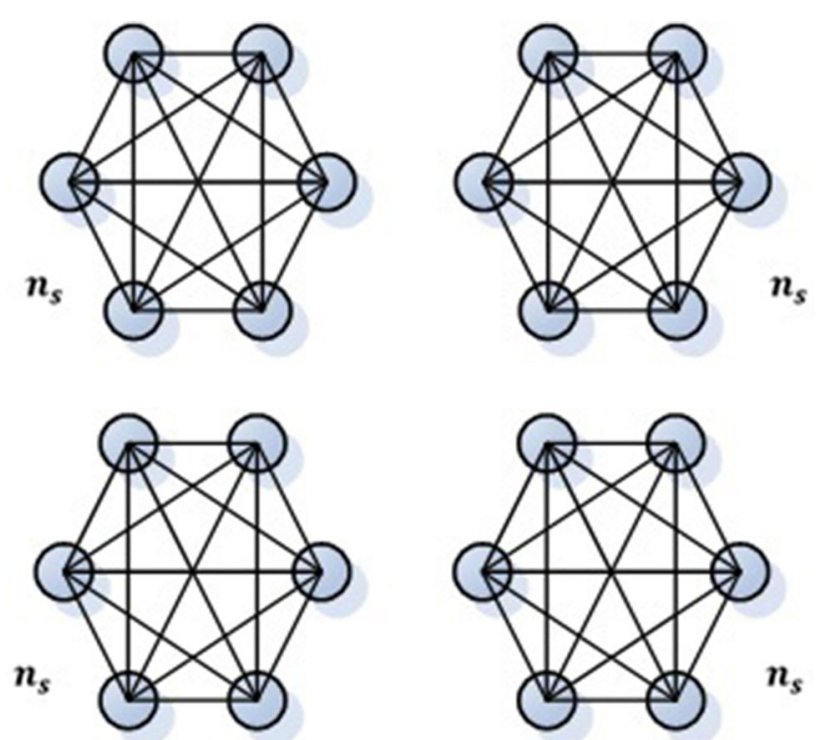

Fig. 1 A team including sub-teams to produce product $\mathrm{X}$ 
If several options were available in order to improve IT, the most cost-effective scenario would be the one with a combination of improving IT and increasing team size.

If the cost of adding new members to the team is more than the cost of improving IT, focusing on IT will be the best decision.

If the product demand is constant, organizations may achieve efficiency by investment in IT, and reducing the team size.

The above discussion has highlighted the importance of investment in IT. By doing so, the coordination and collaboration of activities among team members or sub-teams are facilitated.

The model assumptions are as follows:

- Sizes of sub-teams are the same.

- Each member spends their time on either production or information processing.

- IT as a parameter affects individuals and sub-teams in order to develop the output.

- There is exceptional value for the most effective coordination between individuals and sub-teams.

- Changes in IT contribute to changes in output.

- There is a one-to-one relation between each unit of product, IT, and team size.

- Individuals and sub-teams process all information received from other individuals and sub-teams, respectively.

- One unit of information is processed within one or less than a time unit.

The question that needs to be addressed is: how will you be able to predict the effect of IT on output and appropriate size of each sub-team by a mathematical model?

\section{Mathematical model}

In this study, a mathematical model to evaluate the performance of a team associated with IT and optimized size of sub-teams is presented. Consider a team member who splits his/her time between information processing and production. Suppose that if one unit is exclusively dedicated to production, exactly one unit of output is produced. There is also exactly a unit of information generated, per each unit of output (Tohidi 2006).

It is assumed that a unit of information takes less than one unit of time to be produced. The time required to produce a particular piece of information by individuals is longer than the time consumed by team members if they work as a team to generate the same piece of information.

The model parameters are as follows:

- $n$ : Team size.

- $n_{\mathrm{s}}$ : Size of each sub-team.
- $m$ : Number of sub-teams.

- $\alpha$ : The rate of processing information created by members of a sub-team regarding the production.

- $\beta$ : The rate of processing information created by another sub-team.

- $t_{1}$ : The period of time required to create a report regardless of its size.

- $t_{2}$ : The period of time required to generate a report.

- $\Omega\left(n_{\mathrm{s}}\right)$ : A fraction of the time that each member may spend on production after processing the information received from the other members of a sub-team (Tohidi 2008).

- $p(n)$ : The quantity of production of a team during one time period (Tohidi 2008).

It is assumed that the value of $\alpha$ is greater than the value of $\beta$ and both variables are positive and less than 1 . On the other hand, the coordination between internal sub-team requires more work than sub-teams coordination. Team size $n$ is always more than sub-team size $n_{\mathrm{s}}$.

$0<\beta<\alpha<1$

$1 \leq n_{\mathrm{s}} \leq n$

As was discussed earlier, each individual spends his/her time on either information sharing or production. Individuals spend a fraction of their time on processing information received from others and spend the rest of their time on production which is defined by $\Omega\left(n_{\mathrm{s}}\right)$ and calculated by the following equation:

$$
\begin{aligned}
\Omega\left(n_{\mathrm{s}}\right)= & 1-\alpha \cdot\left(n_{\mathrm{s}}-1\right) \cdot \Omega\left(n_{\mathrm{s}}\right)-\beta \cdot\left(n-n_{\mathrm{s}}\right) \cdot \Omega\left(n_{\mathrm{s}}\right) \\
& -t_{1} / t_{2} \cdot\left(n / n_{\mathrm{s}}-1\right)
\end{aligned}
$$

Equation (3) is simplified to Eq. (4).

$\Omega\left(n_{\mathrm{s}}\right)=\frac{1-t_{1} / t_{2} \cdot\left(n / n_{\mathrm{s}}-1\right)}{1+\alpha \cdot\left(n_{\mathrm{s}}-1\right)+\beta \cdot\left(n-n_{\mathrm{s}}\right)}$

The fraction of the time that each member may spend on production $\Omega\left(n_{\mathrm{s}}\right)$ is between 0 and 1 .

$0 \leq \Omega\left(n_{\mathrm{s}}\right) \leq 1$

The optimum size of a sub-team is determined by the following equation, which is derived from Eq. (4).

$n_{s}^{*}=\frac{t_{1} \cdot n+t_{1} \cdot \sqrt{\frac{n \cdot(1-\alpha) \cdot\left(1+t_{2} / t_{1}\right)+n^{2} \cdot\left(\alpha+\beta \cdot t_{2} / t_{1}\right)}{\alpha-\beta}}}{t_{1}+t_{2}}$

In Fig. 2, it can be seen how sub-team size, the rate of processing information created by other sub-teams, and team size are interrelated and the following observations can be expressed. 


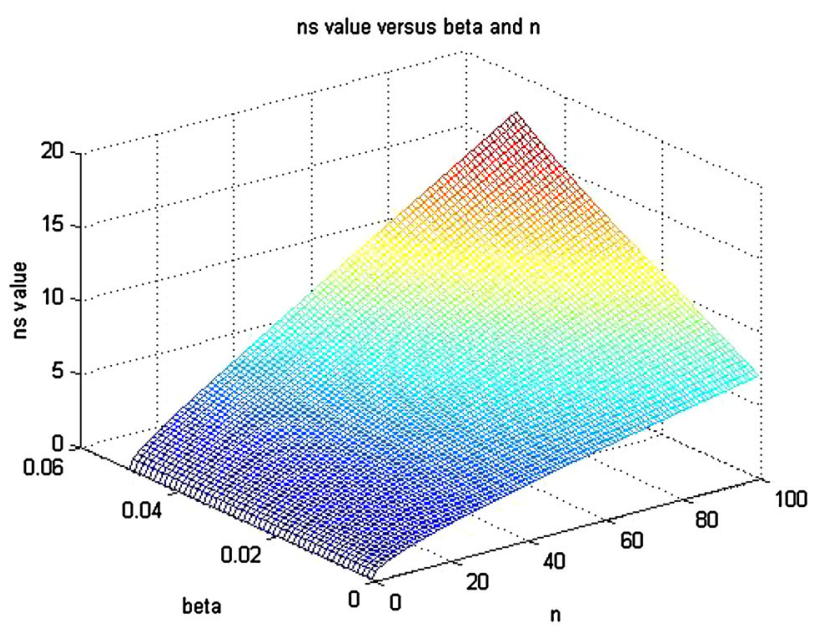

Fig. 2 Size of sub-teams for different beta factors and team sizes

1. When $\alpha$ approaches $\beta$, it means the time it takes to process information created by members of a sub-team approaches the time to process information created by another sub-team, the optimum sub-team size goes to $\mathrm{n}$, pointing that team dividing does not provide any benefits.

2. As the constant time to process a report approaches 0 , the optimum sub-team size approaches 1 That is, each team member becomes a sub-team of size one, pointing to perfect specialization on part of the individuals.

3. When size of a team increases, an efficient sub-team size is the result. So there will be a trade-off between team members coordination and sub-teams coordination. By adding sub-teams to an organization, the coordination endeavor will increase since they will enhance the volume of information that needs to be processed.

The optimum quantity of production is a function of team size and $\Omega\left(n_{\mathrm{s}}^{*}\right)$. It is concluded that by adding to the team members, productivity increases.

$P_{n_{\mathrm{s}}^{*}}(n)=n \cdot \Omega\left(n_{\mathrm{s}}^{*}\right)$

Theorem $1 \quad P_{n_{\mathrm{s}}^{*}}(n)$ is a monotonically and increasing function in $n$ for all values of $0<\beta<\alpha<1$.

$$
\begin{aligned}
& \text { Proof } \\
& \frac{\mathrm{d} P_{n_{\mathrm{s}}^{*}}(n)}{\mathrm{d} n}= \\
& \frac{(1-\alpha) \cdot\left(t_{2}+t_{1}\right)^{3} \cdot \sqrt{t_{1} \cdot n \cdot(\alpha-\beta) \cdot\left[\left(t_{1}+t_{2}\right) \cdot(1-\alpha)+n \cdot\left(\alpha \cdot t_{1}+\beta \cdot t_{2}\right)\right.}}{R \cdot S^{2}},
\end{aligned}
$$

where $\mathrm{R}$ and $\mathrm{S}$ are calculated by Eqs. (9) and (10).

$$
\begin{aligned}
R= & t_{1} \cdot n \cdot t_{2} \cdot(\alpha-\beta)+t_{2} \\
& \cdot \sqrt{n \cdot t_{1} \cdot(\alpha-\beta) \cdot\left[\left(t_{1}+t_{2}\right) \cdot(1-\alpha)+n \cdot\left(\alpha \cdot t_{1}+\beta \cdot t_{2}\right)\right.}
\end{aligned}
$$

$$
\begin{aligned}
S= & t_{1} \cdot t_{2} \cdot(n-1)+t_{2} \cdot(n \cdot \beta+1-\alpha)+t_{1} \\
& +\sqrt{n \cdot t_{1} \cdot(\alpha-\beta) \cdot\left[\left(t_{1}+t_{2}\right) \cdot(1-\alpha)+n \cdot\left(\alpha \cdot t_{1}+\beta \cdot t_{2}\right)\right.}
\end{aligned}
$$

$\frac{\mathrm{d} P_{n_{\mathrm{s}}^{*}}(n)}{\mathrm{d} n}>0$

Hence, $P_{n_{\mathrm{s}}^{*}}(n)$ is monotonically increasing function in $n$.

Theorem 1 indicates that team output can be increased by adding members to the team. However, the marginal product of team members is decreasing due to the increased coordination effort required, so that, for each added team member, there is a smaller and smaller increase in output. Beyond some value of $n$, the marginal cost of an additional team member exceeds the marginal value of the team's production (Tohidi 2006).

Theorem 2 For all values of $0<\beta<\alpha<1, P_{n_{\mathrm{s}}^{*}}(n)$ is a bounded function.

Proof From Theorem 1, $P_{n_{\mathrm{s}}^{*}}(n)$ is a concave and monotonically increasing function of $\mathrm{n}$. Also, $P_{n_{\mathrm{s}}^{*}}(0)=0$.

$\lim _{n \rightarrow \infty} P_{n_{\mathrm{s}}^{*}}(n)=\frac{2+t_{2} / t_{1}-t_{1} / t_{2} \cdot \sqrt{\frac{\left(\alpha+\beta \cdot t_{2} / t_{1}\right)}{\alpha-\beta}}}{\alpha+\beta \cdot t_{2} / t_{1}+\sqrt{(\alpha-\beta)\left(\alpha+\beta \cdot t_{2} / t_{1}\right)}}$

Hence, $P_{n_{\mathrm{s}}^{*}}(n)$ is a bounded function.

The practical implication of Theorem 2 is that the maximum total production of a team during one time period depends on the speed at which the team members can coordinate their activities with their peers. To increase the team's maximum production capacity, it is necessary to change the communication and processing technology (i.e., decrease the value of $\alpha$ and $\beta$ ) or the work has to be reorganized so that each team member does not process all of the information provided by the other members (Tohidi 2008).

Theorem 3 The marginal product of team size is asymptotically zero.

Proof

$\lim _{n \rightarrow \infty} \frac{\mathrm{d} P_{n_{\mathrm{s}}^{*}}(n)}{\mathrm{d} n}=0$ 
According to Eq. (13), if taken to a certain extent, adding to the team members may not result in productivity. Therefore, in order to increase total production units information sharing will need to be improved.

It can be understood from Eqs. 8 and 13 that management can grow the organization output by adding to the team members.

Figure 3 illustrates how $\frac{\mathrm{d} P_{n_{\mathrm{s}}^{*}}(n)}{\mathrm{d} n}$ performs in different team size and the rate of processing information created by other sub-teams.

\section{Interaction between IT and sub-teams}

IT system may change team members' interactions through changing in one or some of the three information parameters $\alpha, \beta$ and $t_{1}$.

The derivative of sub-team size with respect to IT parameter $\alpha$ is calculated in Eq. (14).

$\frac{\mathrm{d} n_{\mathrm{s}}^{*}}{\mathrm{~d} \alpha}=\frac{t_{1} \cdot n \cdot[\beta \cdot(1-n)-1] \cdot\left(1+t_{2} / t_{1}\right)}{2 \cdot\left(t_{1}+t_{2}\right) \cdot(\alpha-\beta)^{2} \cdot \sqrt{\frac{n \cdot(1-\alpha) \cdot\left(1+t_{2} / t_{1}\right)+n^{2} \cdot\left(\alpha+\beta \cdot t_{2} / t_{1}\right)}{\alpha-\beta}}}$

The value of $\mathrm{d} n_{\mathrm{s}}^{*}$ by $\mathrm{d} \alpha$ is negative.

$\frac{\mathrm{d} n_{\mathrm{s}}^{*}}{\mathrm{~d} \alpha}<0$

Equation 15 indicates, when sub-team's communication capabilities develop, the size of sub-team increases.

Figure 4 shows how $\frac{\mathrm{d} n_{\mathrm{s}}^{*}}{\mathrm{~d} \alpha}$, the rate of processing information created by other sub-teams, and team size affect each other.

The derivative of sub-team size with respect to IT parameter $\beta$ is calculated in Eq. (16).

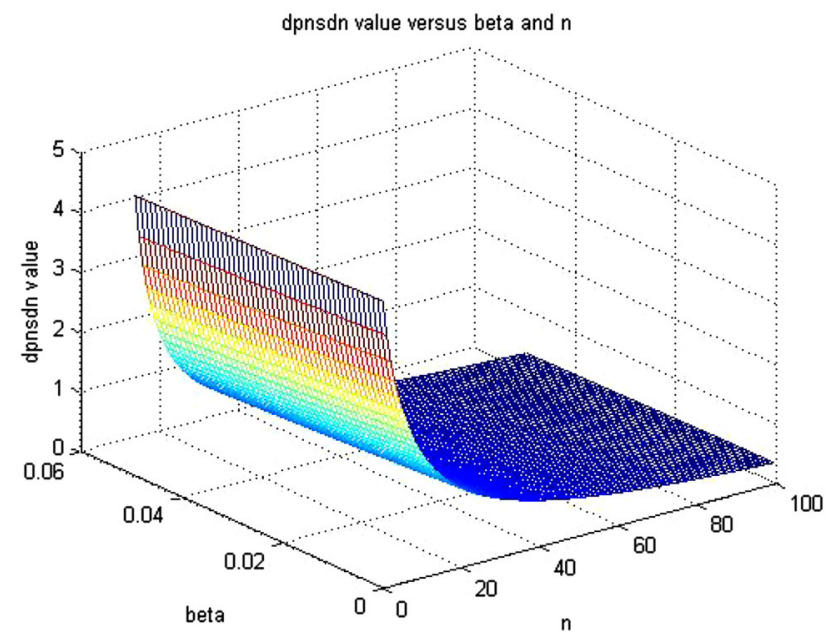

Fig. $3 \frac{\mathrm{d} P_{n_{\mathrm{s}}^{*}}(n)}{\mathrm{d} n}$ for beta factors and team sizes

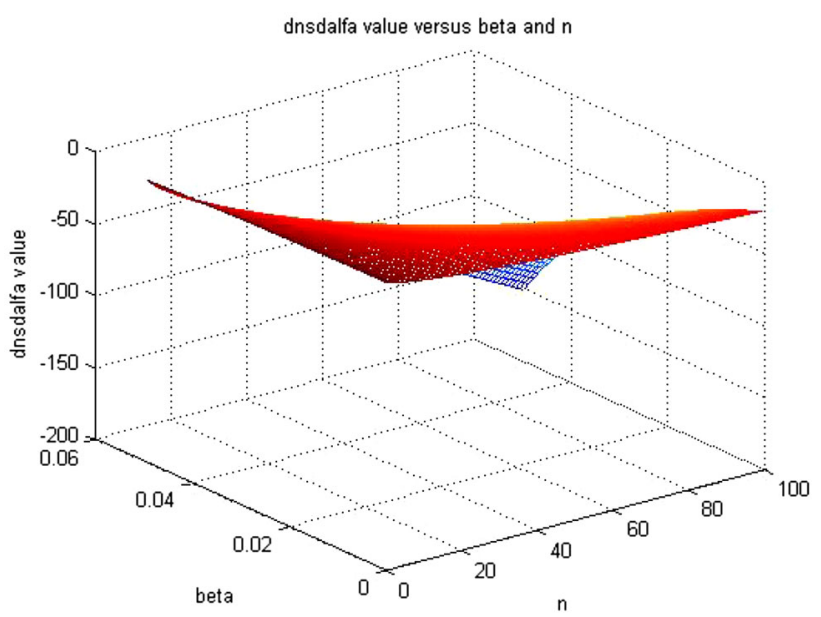

Fig. $4 \frac{\mathrm{d} n_{\mathrm{s}}^{*}}{\mathrm{~d} \alpha}$ for different beta factors and team sizes

$$
\begin{aligned}
& \frac{\mathrm{d} n_{\mathrm{s}}^{*}}{\mathrm{~d} \beta}= \\
& \frac{t_{1} \cdot n \cdot\left[(\alpha-\beta) \cdot t_{2} / t_{1}+n \cdot(1-\alpha) \cdot\left(1+t_{2} / t_{1}\right)+n^{2} \cdot\left(\alpha+\beta \cdot t_{2} / t_{1}\right)\right.}{2 \cdot\left(t_{1}+t_{2}\right) \cdot(\alpha-\beta)^{2} \cdot \sqrt{\frac{n \cdot(1-\alpha) \cdot\left(1+t_{2} / t_{1}\right)+n^{2} \cdot\left(\alpha+\beta \cdot t_{2} / t_{1}\right)}{\alpha-\beta}}}
\end{aligned}
$$

The value of $\mathrm{d} n_{\mathrm{s}}^{*}$ by $\mathrm{d} \beta$ is positive.

$\frac{\mathrm{d} n_{\mathrm{s}}^{*}}{\mathrm{~d} \beta}>0$

Equation 17 indicates, as the inter-sub-team coordination is simplified by using the new technology, the optimum sub-team size decreases.

Figure 5 shows how $\frac{\mathrm{d} n_{\mathrm{s}}^{*}}{\mathrm{~d} \beta}$, the rate of processing information created by other sub-teams, and team size affect each other.

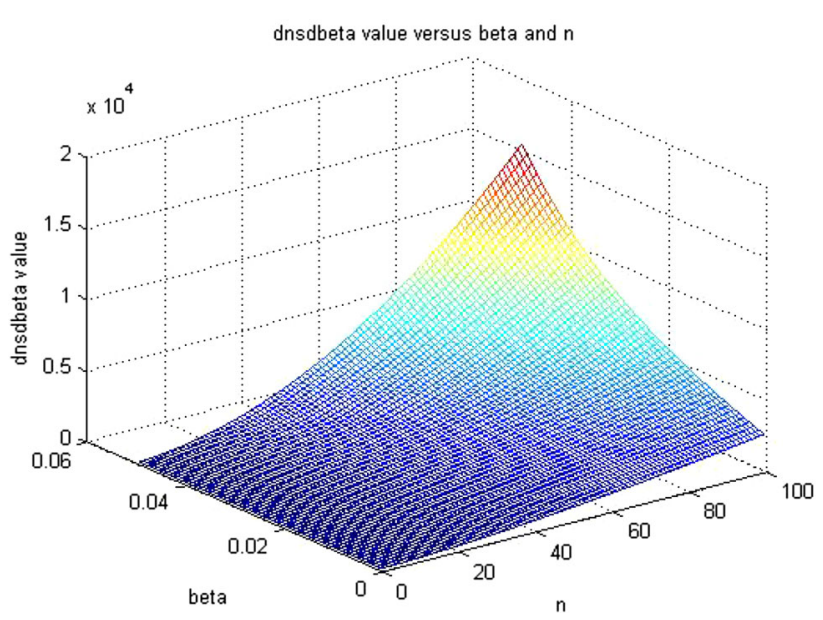

Fig. $5 \frac{\mathrm{d} n_{\mathrm{s}}^{*}}{\mathrm{~d} \beta}$ for different beta factors and team sizes 
The derivative of sub-team size with respect to the period of time required to create a report regardless of its size is calculated in Eq. (18).

$$
\begin{aligned}
& \frac{\mathrm{d} n_{\mathrm{s}}^{*}}{\mathrm{~d} t_{1}}=\frac{n \cdot t_{2}}{\left(t_{1}+t_{2}\right)^{2}} \\
& +\frac{n \cdot t_{2} \cdot \frac{(1-\alpha)}{2}+n^{2} \cdot t_{2} \cdot\left(\alpha-\frac{\beta}{2}\right)+t_{2} \cdot\left[n \cdot t_{1} \cdot t_{2} \cdot(1-\alpha)+\frac{\beta \cdot t_{2} \cdot n^{2}}{t_{1}}\right.}{(\alpha-\beta) \cdot\left(t_{1}+t_{2}\right)^{2} \cdot \sqrt{\frac{n \cdot(1-\alpha) \cdot\left(1+t_{2} / t_{1}\right)+n^{2} \cdot\left(\alpha+\beta \cdot t_{2} / t_{1}\right)}{\alpha-\beta}}}
\end{aligned}
$$

The value of $\mathrm{d} n_{\mathrm{s}}^{*}$ by $\mathrm{d} t_{1}$ is positive.

$\frac{\mathrm{d} n_{\mathrm{s}}^{*}}{\mathrm{~d} t_{1}}>0$

Equation 19 indicates as the time spent to process the information, the coordination time of tasks decreases, the size of organizational units will change. This change depends on changing the three information parameters. Of course, in all cases the coordination time decreases and the time spent on production increases.

Figure 6 illustrates how $\frac{\mathrm{d} n_{\mathrm{s}}^{*}}{\mathrm{~d} t_{1}}$ performs with variation in $\beta$ and $n$.

\section{Sensitivity analysis}

Equations 15, 17 and 19 emphasize the significance of investments in IT. By investing in IT that simplifies activities coordination among team members, the organization's production can be increased by management. The IT investment that adds intra-sub-team coordination, improves inter-sub-team coordination, or both. The suitable combination of investments depends on the labor cost, the task, and the price of the product at which the organization can sell.

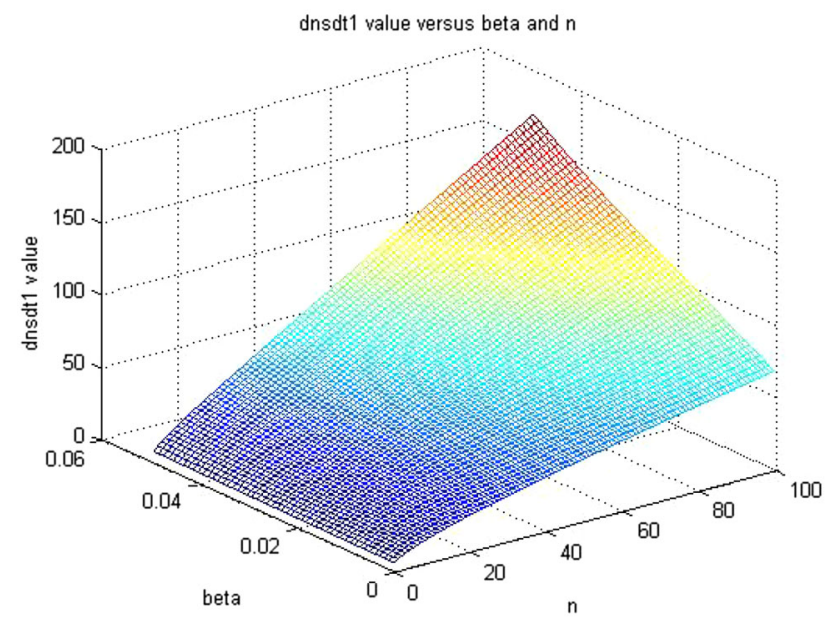

Fig. $6 \frac{\mathrm{d} n_{\mathrm{s}}^{*}}{\mathrm{~d}_{1}}$ for different beta factors and team sizes
Table 1 Values of parameters for three different trials

\begin{tabular}{llll}
\hline Parameters & 1st trial & 2nd trial & 3rd trial \\
\hline$n$ & 21 & 54 & 21 \\
$\alpha$ & 0.2 & 0.2 & 0.2 \\
$\beta$ & 0.03 & 0.03 & 0.006 \\
$t_{1}$ & 0.2 & 0.2 & 0.2 \\
$t_{2}$ & 7 & 7 & 7 \\
$n_{\mathrm{s}}^{*}$ & 3 & 6 & 2 \\
$\Omega\left(n_{\mathrm{s}}\right)$ & 0.427 & 0.224 & 0.554 \\
$P_{n_{\mathrm{s}}^{*}}(n)$ & 9 & 12 & 12 \\
$m$ & 7 & 9 & 11 \\
\hline
\end{tabular}

Once the parameters, variables, and equations are defined and the results are obtained, a sensitivity analysis is performed to validate the presented mathematical model. The sensitivity analysis is developed in order to identify the variable which has the highest impact on the outcome of the model.

Three trials are reviewed and their numerical results are analyzed. The rate of processing information created by other sub-teams $(\beta)$ and team size $(n)$ are varied in turn while the other variables remained the same. The results of the 2nd and 3rd trials are compared with outcomes of the 1 st trial to determine how team size and information sharing system among sub-team members may affect the consequences, respectively.

As depicted in Table 1, in the original trial a team size of 21 is studied when the rate of processing information created by other sub-teams equals 0.03 . According to the model, this team contributes to 9 units of product $X$. In the next trial, in order to increase $P(n)$ from 9 to 12 units, team size needs to be changed to 54 while keeping the other variables unchanged. In the last trial, 12 units of product were obtained by improving information sharing system among sub-team members from 0.03 to 0.006 . In other words, the same level of production may be achieved by $80 \%$ improvement in IT instead of adding 33 members to the team which is almost $157 \%$ more than the original team size.

\section{Conclusion}

In this study, a mathematical model has been proposed through which team performance was overviewed. The model is aimed at saving costs and improving productivity by collaboration and coordination of individuals within sub-teams and sub-teams within the whole team. Such a team is difficult to build and maintain, and it requires determining of optimum team size and sub-team size and the role that IT may possibly play. It has been found that 
productivity increases with the increment of team size. However, increasing team size is not always cost-effective; beyond a certain point the cost of adding to the team members exceeds the value added to productivity. Investment in IT may also result in improvement in productivity. Hence, there should be a balance between increasing team size and improving IT in order to improve productivity. It is concluded that same numbers of product units may be attained by improving IT and increasing team size. Therefore, IT is an alternative for increasing team size. In summary, if improving information sharing system is more cost efficient then adding to the members of sub-teams and team is not the best scenario.

It is also concluded that if we separate a team into subteams and invest in IT, the efficiency and capacity of organization will be increased. Those interested in further studies in this research may investigate the methodologies and estimation approaches and measurement of IT parameters. Another future work in this research would be searching and providing an appropriate model which could be applied to a team with structured sub-teams, under the specific circumstances. There might be many uncertainties in more progressive cases in practice. Hence, the experiment may be further extended to test the improvement of productivity by increasing team size and IT using fuzzy logic.

Open Access This article is distributed under the terms of the Creative Commons Attribution 4.0 International License (http://crea tivecommons.org/licenses/by/4.0/), which permits unrestricted use, distribution, and reproduction in any medium, provided you give appropriate credit to the original author(s) and the source, provide a link to the Creative Commons license, and indicate if changes were made.

\section{References}

Badescu M, Garcés-Ayerbe C (2009) The impact of information technologies on firm productivity: empirical evidence from Spain. Technovation 29(2):122-129

Bartel AP, Ichniowski C, Shaw KL (2005) How does information technology really affect productivity? Plant-level comparisons of product innovation, process improvement and worker skills. NBER Working Paper No. 11773, November 2005

Bharadwaj AS (2000) A resource-based perspective on information technology capability and firm performance: an empirical investigation. MIS Q 24:169-196

Dehning B, Richardson VJ (2002) Returns on investments in information technology: a research synthesis. J Inf Syst 16(1):7-30

Galegher J, Kraut RE (1994) Computer-mediated communication for intellectual teamwork: an experiment in group writing. Inf Syst Res 5(2):110-138

Hatcher L, Ross TL (1991) From individual incentives to an organization-wide gainsharing plan: effects on teamwork and product quality. J Organ Behav 12(3):169-183

Jones DC, Kalmi P, Kauhanen A (2011) Firm and employee effects of an enterprise information system: micro-econometric evidence. Int J Prod Econ 130(2):159-168

Kılıçaslan Y, Sickles RC, Kayış AA et al (2017) Impact of ICT on the productivity of the firm: evidence from Turkish manufacturing. J Prod Anal. doi:10.1007/s11123-017-0497-3

Martínez-Lorente AR, Sánchez-Rodr'́guez C, Dewhurst FW (2004) The effect of information technologies on TQM: an initial analysis. Int J Prod Econ 89(1):77-93

Moses TP, Stahelski AJ (1999) A productivity evaluation of teamwork at an aluminum manufacturing plant. Group Organ Manag 24(3):391-412

Powell SG (2000) Specialization, teamwork, and production efficiency. Int J Prod Econ 67(3):205-218

Salas E, Cooke NJ, Rosen MA (2008) On teams, teamwork, and team performance: discoveries and developments. Hum Factors J Hum Factors Ergon Soc 50(3):540-547

Shao BBM, Lin WT (2016) Assessing output performance of information technology service industries: productivity, innovation and catch-up. Int J Prod Econ 172:43-53

Stewart GL, Barrick MR (2000) Team structure and performance: assessing the mediating role of intrateam process and the moderating role of task type. Acad Manag J 43(2):135-148

Tohidi H (2006) The team-based, information technology-enabled organizations. In: Proceedings of the second international conference on information management and business (IMB2006), pp 145-154

Tohidi H (2008) The relationship between teamwork effectiveness and information technology. J Appl Econ Sci 3(4(6)_Winter2008):464

Tohidi H, Tarokh MJ (2006) Productivity outcomes of teamwork as an effect of information technology and team size. Int J Prod Econ 103(2):610-615

Whelan K (2002) Computers, obsolescence, and productivity. Rev Econ Stat 84(3):445-461

Wu L, Chuang C-H, Hsu C-H (2014) Information sharing and collaborative behaviors in enabling supply chain performance: a social exchange perspective. Int J Prod Econ 148:122-132 